\title{
Research of Combined Control Scheme for Fast Catamaran Motion Control Using T-foils and Interceptors
}

\author{
Zhiqun Guo*, Zhuang Lin, Qiang Yang, Xiaowen Li \\ College of Shipbuilding Engineering, Harbin Engineering University \\ Harbin, China \\ * Corresponding author's Email: guozhiqun@gmail.com
}

\begin{abstract}
Fast catamaran oscillates in shortwave sea conditions due to its low length to beam ratio and relatively light weight. T-foils or interceptors are effective stabilizers for alleviating the pitch and heave motions of fast craft. This work designs a catamaran motion decoupling combined control system utilizing 2 T-foils and 2 interceptors, which can not only control the longitudinal motion, but also alleviate the roll motion of fast catamaran. Numerical simulation results show that the motion control system can satisfactorily improve seakeeping performance of fast catamaran.
\end{abstract}

Keywords: catamaran; seakeeping performance; pitch; heave; roll; T-foil; interceptor; 3-DOF; combined control

\section{Introduction}

The number of high speed ferry with various types of operating throughout the world has bloomed recently for the growing needs of domestic, cross-strait and international passenger and cargo ferry markets. Fast catamaran with a super slender twin-hull form that is characterized as safe, comfortable, economic, having large capacity for shipment and fast speed is one of the most attractive options for the large highspeed ferry applications. However, it has been reported [1-4] that high speed catamaran shows a low seakeeping performance in moderate to rough sea conditions. This is because the catamaran holds high transverse stability that can restrain the roll angle of the ship, while the roll acceleration remains large, which causes the discomfort of passengers. Besides, because of the low length to beam ratio, the natural roll frequency of the catamaran approaches the natural heave and pitch frequency, so the catamaran tends to oscillate harmonically with the short wave, in particular to the combination of longitudinal vibration.

The oscillations of fast catamaran lead to a sequence of negative impact on its seakeeping and working qualities, such as passengers' sickness, reduction of velocities of the move and deterioration to controllability, appearance of the additional loads in the structural hull and deterioration of the habitability conditions on the catamaran [5]. Therefore, it is crucial to ameliorate the seakeeping of fast catamaran ferry.

As for the seakeeping amelioration, or the ship motion control, this is a wide domain of ship engineering spanning from transverse oscillations (roll, yaw and sway) control to longitudinal vibrations (heave, pitch and surge) control, which attracts the attention of thousands of researchers and engineers from the worldwide institutes, laboratories and factories; and the publications of researches are plentiful. As we all know, for symmetrical ships, the transverse and longitudinal motions can be decoupled in a linear approximation, so their motion control researches are separately conducted. Roll is the main part of transverse motions which has profound pernicious effect on all types of ships, and active fin stabilization system is advocated to be the most effective for roll stabiliza- 
tion [6]. Meanwhile, it has been observed that rudder can induce ephemeral roll before the ship enters into any yaw motion, the characteristic of which encouraged Cowley [7] to conduct studies on the feasibility of using rudder in congress with the fins to enhance roll stabilization. From then on, the conjunction control of rudders with fins is a mainstream methodology for roll amelioration, and the researches spread from control algorithms exploring [8] to final sea trial [9].

On the other hand, as the advent of fast ferries, during navigation in head seas the wave encounter frequency rises up. As a result, the heave and pitch motions became serious [10]. Hence, another stabilization problem - longitudinal oscillations emerged. A most common stabilizer for ameliorating longitudinal oscillation is passive foils under the ship bow, which has dual functions: producing lift force and lift damping [11]. The former function can slightly raise the ship bow up and diminish the wet hull area, which induces the reduction of resistance and alleviation the impact of waves. The latter counteracts the heave force and pitch moment. Thus thanks to the functions, passive foils could alleviate the heave/pitch motions. However, few works have studied the active foils, which might generate more effective impact on the amelioration of longitudinal oscillations, while the utilization of passive ones has lasted decades. Esteban et al [12] noticed this problem and started a research looking for seakeeping improvement of fast monohull ferry utilizing actuators such as T-foil and transom flaps. The research underwent decade and got fruitful results. Firstly, researchers paid attention to the longitudinal oscillations alleviation [13]. Lately, they noticed that the transverse oscillations especially the roll and yaw motions also induce harmful effect on the seakeeping performance [17]. Then they launched a new research, in which the transverse oscillations alleviation using fin stabilizers were carried out simultaneously with the improvement of longitudinal vibrations [18][19].

However, so far the publications of active motion control of fast catamaran are seldom seen. Until recently, [20] studied a SES 3-DOF motions (heave/pitch/roll) control, where the heave and pitch oscillations are alleviated by air-vent louver control and the roll motion is controlled by active fins; [21][22] exploited active fins to control the longitudinal motions of SWATH. All the upper researches proposed motion control methodologies that aim at special catamaran forms. Indeed, by traditional ways, for a conventional fast catamaran, the actuators for 3-DOF motion con- trol are usually to be T-foil, flaps/interceptors and fin stabilizers, which could be studied on more general forms of fast ship, as the research of Esteban et al [12]. However, for a high speed displacement catamaran, fin stabilizers should be sizeable to generate enough control moment and shrinkable to reduce the water residence, which suggest that an extra considerable room is needed in each sidehull for storing fins and their affiliations, so fin stabilizers are compromising for high speed catamarans.

In this work, we go beyond the conventional way and try to propose a novel 3-DOF motions control method. According to this method, an active T-foil under each sidehull bow and an interceptor behind each sidehull stern of fast catamaran are exploited, while fin stabilizers, which require sizeable hull room for storing fins, are abandoned. The working way of the proposed method can be outlined as follows: in heading or following seas, the longitudinal vibrations dominate the ship oscillations, so the stabilization actuators ( 2 T-foils and 2 interceptors) work in traditional way to control the longitudinal motions; in beam seas, the transverse vibrations dominate the ship oscillations, in which conditions actuators counteract the roll movement. In this way, the control of 3-DOF motions of fast catamaran is accomplished, while the utilized stabilizers are only T-foils and interceptors.

This paper is organized as follows. In Section 2 the mathematical motion model of fast catamaran is proposed, and the hydrodynamic characteristics of the catamaran and its stabilizers (T-foils and interceptors) are discussed. Then the motion autonomous control system is built up in Section 3. In Section 4 the simulation results are present. The paper is concluded in Section 5.

\section{Basic assumption and system modeling}

To control the motions of fast catamaran, one should build a mathematical model of the dynamic system for design and analytical purposes. But founding an exact mathematical model of the catamaran motion dynamics is a hard work, due to the non-linear phenomena of free surface conditions. Luckily, the linear shipmotion theory can be precise enough, if the amplitude of sea waves is small [10].

According to the linear ship-motion theory, the equations of 3-DOF motions of fast catamaran (without 
control) can be written as follows [11]:

$$
\begin{gathered}
\left(m+a_{33}^{h}\right) \ddot{z}+b_{33}^{h} \dot{z}+c_{33}^{h} z+a_{35}^{h} \ddot{\theta} \\
+b_{35}^{h} \dot{\theta}+c_{35}^{h} \theta=F_{3} \\
\left(I_{55}+a_{55}^{h}\right) \ddot{\theta}+b_{55}^{h} \dot{\theta}+c_{55}^{h} \theta+a_{53}^{h} \ddot{z} \\
+b_{53}^{h} \dot{z}+c_{53}^{h} z=F_{5} \\
\left(I_{44}+a_{44}^{h}\right) \ddot{\phi}+b_{44}^{h} \dot{\phi}+c_{44}^{h} \phi=F_{4}
\end{gathered}
$$

where, $z, \theta$ and $\phi$ are the heave, pitch and roll displacement, respectively; $m, I_{44}$ and $I_{55}$ are the mass and the mass moment of inertia of the catamaran; $a_{i j}^{h}$, $b_{i j}^{h}$ and $c_{i j}^{h}(i, j=3,4,5)$ are added masses, damping coefficients and restoring coefficients of bare hull, respectively ( $i=3$ - heave; $i=4$-roll $; i=5$ - pitch); $F_{3}, F_{4}$ and $F_{5}$ are wave exciting force and moment.

\subsection{Hydrodynamic characteristics of the fast cata- maran}

In order to calculate the added masses and damping coefficients from equations (1), 2.5D theory [23] is adopted. The $2.5 \mathrm{D}$ theory, where the free surface condition is 3D but the control equation and body surface condition are 2D, is high-accuracy and timesaving for evaluating the hydrodynamics of high speed slender-body ships, such as catamaran, trimaran. The details of $2.5 \mathrm{D}$ theory and its formula can be found in [24], where authors employed 2.5D theory to predict the motion response characteristics of high speed bare hull catamaran. And comparing the results with experimental ones, the theory gives satisfactory prediction.

\subsection{Hydrodynamic characteristics of the T-foil}

In our case, the T-foil effect should be considered and added into the catamaran hydrodynamic characteristics. Some of expressions of T-foil lift effect can be found in [11], while others need to be carefully derived. Here authors give all expressions:

$$
\begin{aligned}
& a_{33}^{L}=2\left(m^{h}+a_{33}^{h}\right), \\
& a_{35}^{L}=a_{53}^{L}=-2 l_{h}\left(m^{h}+a_{33}^{h}\right), \\
& a_{55}^{L}=2 l_{h}^{2}\left(m^{h}+a_{33}^{h}\right), \\
& a_{44}^{L}=2 b^{2}\left(m^{h}+a_{33}^{h}\right) ; \\
& b_{33}^{L}=r U A_{h} C_{L}, \\
& b_{35}^{L}=b_{53}^{L}=-r U A_{h} l_{h} C_{L}, \\
& b_{55}^{L}=r U A_{h} l_{h}^{2} C_{L}, \\
& b_{44}^{L}=r U A_{h} b^{2} C_{L} ; \\
& c_{35}^{L}=c_{53}^{L}=r U^{2} A_{h} C_{L}, \\
& c_{55}^{L}=-r U^{2} A_{h} l_{h} C_{L} .
\end{aligned}
$$

where $m^{h}$ and $a_{33}^{h}$ are the mass and added mass of a T-foil, respectively; $\rho$ is the density of water; $U$ is the navigation speed of the catamaran; $A_{h}$ is the area of T-foils; $l_{h}$ is longitudinal coordinate of T-foils; $b$ is half breadth of catamaran; $C_{L}$ is derivative of lift coefficient with respect to angle of attack of T-foils.

In automatic control system, the attack of T-foils $\alpha$ varies to provide anti-heave (pitch) force (moment). The expression of lift force of T-foil is

$$
F_{f}=\frac{1}{2} r U^{2} A C_{L} \alpha
$$

where lift coefficients $C_{L} \alpha$ can be determined by panel theory or experiments.

\subsection{Hydrodynamic characteristics of the intercep- tor}

Interceptor is essentially made up of a thin plate fitted on the transom of a boat, which can insert into water and extend either vertically or transversely beyond the section at the stern. The interceptor modifies the local flow near the stern to generate an additional pressure normal to the hull surface. Modeling experimental results show that with the deployment of the interceptor, a reduction in calm-water resistance with benefits of $10-18 \%$ in the speed ranging from 8 to 20 knots accompanied by reduced sinkage and trim was achieved [25]. In this work, the lift effect generated by interceptors is concerned:

$$
\begin{aligned}
& a_{33}^{I}=2\left(m^{i}+a_{33}^{i}\right), \\
& a_{35}^{I}=a_{53}^{I}=-2 l_{i}\left(m^{i}+a_{33}^{i}\right), \\
& a_{55}^{I}=2 l_{i}^{2}\left(m^{i}+a_{33}^{i}\right), \\
& a_{44}^{I}=2 b^{2}\left(m^{i}+a_{33}^{i}\right) ; \\
& b_{33}^{L}=2 b_{33}^{i}, \\
& b_{35}^{L}=b_{53}^{L}=-2 l_{i} b_{33}^{i}, \\
& b_{55}^{L}=2 l_{i}^{2} b_{33}^{i}, \\
& b_{44}^{L}=2 b^{2} b_{33}^{i} ; \\
& c_{35}^{L}=c_{53}^{L}=-2 c^{i} g, \\
& c_{55}^{L}=2 c^{i} l_{i} g .
\end{aligned}
$$

where $m^{i}$ and $a_{33}^{i}$ are the mass and added mass of an interceptor, respectively; $a_{33}^{i}$ is damping and $c^{i}$ is restoring coefficient.

In automatic control system, the insert depth of interceptor plate varies. However, there are no exact relations between the insert depth of the plate and lift force. An empirical formula derived from our towing experiment can be employed to depict the relationship:

$$
F_{i}=\left(C+A_{1} h+A_{2} h^{2}+B_{1} q+B_{2} q^{2}\right) g
$$

where $A_{i}, B_{i}, \mathrm{C}$ are constants; $h$ is the inserting into water depth; $\theta$ is the pitch angle; $g$ is the accelerate of gravity. 


\section{Catamaran motion control system}

In this section, first the mathematical control model of the catamaran motions is built; then the motion control algorithm is carefully selected; at last a simulation model of fast catamaran motion control system is set up.

\subsection{Mathematical Control Model of the Fast Cat- amaran}

The mathematical control model can be depicted as:

$$
\begin{gathered}
\left(m+a_{33}\right) \ddot{z}+b_{33} \dot{z}+c_{33} z+a_{35} \ddot{\theta}+b_{35} \dot{\theta} \\
+c_{35} \theta=F_{3}-K_{3} \\
\left(I_{55}+a_{55}\right) \ddot{\theta}+b_{55} \dot{\theta}+c_{55} \theta+a_{53} \ddot{z}+b_{53} \dot{z} \\
+c_{53} z=F_{5}-K_{5} \\
\left(I_{44}+a_{44}\right) \ddot{\phi}+b_{44} \dot{\phi}+c_{44} \phi=F_{4}-K_{4}
\end{gathered}
$$

where $a_{i j}, b_{i j}$ and $c_{i j}(\mathrm{i}, \mathrm{j}=3,4,5)$ are added masses, damping coefficients and restoring coefficients of hull with T-foils and interceptors, respectively; $K_{i}(\mathrm{i}=3,4$, $5)$ are control force/moments generated by T-foils and interceptors.

$$
\begin{aligned}
& a_{i j}=a_{i j}^{h}+a_{i j}^{L}+a_{i j}^{I}, \\
& b_{i j}=b_{i j}^{h}+b_{i j}^{L}+b_{i j}^{I}, \\
& c_{i j}=c_{i j}^{h}+c_{i j}^{L}+c_{i j}^{I} . \\
k_{3}= & 2\left(F_{f}+F_{i}\right), \\
k_{5}= & 2\left(-F_{f} l_{f}+F_{i} l_{i}\right), \\
k_{4}= & b\left(F_{f L}+F_{i L}-F_{f R}-F_{i R}\right) .
\end{aligned}
$$

In equations (6) except the control force/moments, all coefficients and wave force/moments can be evaluated by the aforesaid methods. In order to solve the heave, pitch and roll displacement, $K_{i}(\mathrm{i}=3,4,5)$ should be related to these displacements, and then the equations (6) will be solvable, after which, the attack of T-foils $\alpha$ and insert depth of interceptors $h$ can be figured out with respect to equations (3), (5) and (8). In equations (8) $F_{f L}, F_{i L}$ are forces of T-foil, interceptor on the left side and $F_{f R}, F_{i R}$ are forces of T-foil, interceptor on the right side.

Wang et al [26] have proved that the roll control effect achieves best, if the control moment is proportionate to the roll angular velocity:

$$
k_{4}=b_{44}^{k} \dot{\phi}
$$

where $b_{44}^{k}$ is the proportional coefficient. Obviously, the conduction can be extended to the heave/pitch control, i.e.

$$
\begin{aligned}
& k_{3}=b_{33}^{k} \dot{z} \\
& k_{5}=b_{55}^{k} \dot{\theta}
\end{aligned}
$$

where $b_{33}^{k}, b_{55}^{k}$ are the proportional coefficients. Moving the control force/moments to the left side of equations (6), and substituting (9), (10) into (6), we get

$$
\begin{gathered}
\left(m+a_{33}\right) \ddot{z}+\left(b_{33}+b_{33}^{k}\right) \dot{z}+c_{33} z+a_{35} \ddot{\theta} \\
+b_{35} \dot{\theta}+c_{35} \theta=F_{3} \\
\left(I_{55}+a_{55}\right) \ddot{\theta}+\left(b_{55}+b_{55}^{k}\right) \dot{\theta}+c_{55} \theta+a_{53} \ddot{z} \\
+b_{53} \dot{z}+c_{53} z=F_{5} \\
\left(I_{44}+a_{44}\right) \ddot{\phi}+\left(b_{44}+b_{44}^{k}\right) \dot{\phi}+c_{44} \phi=F_{4}
\end{gathered}
$$

From (11) we can make conclusion that the control force/moments are equivalent to adding damping effect to the catamaran.

\subsection{Motion Control Scheme}

The longitudinal motion control system is two in (the attack angle of T-foils and the insert depth of interceptors) two out (the heave and pitch of the catamaran), and the heave and pitch motions are coupled. In order to make effective control, the coupled motions need to be decoupled [27]. Hence, in this work, a post-compensation decoupling method is utilized.

In terms of the control algorithms, the publications on which are innumerable, but most of them are confined to academic researches, and few can be realized in reality. In [12] and [22], where towing experiments were conducted, all authors without exception employed the PD controller. Therefore, under the consideration of our future model experiments, in this work the PD controller is selected.

One should note that in expressions (9) and (10) the control force/moment is proportionate to the heave/pitch/roll angular velocity. But in reality due to sluggish action of T-foils and interceptors, a differential node is required in control system besides the proportional node. This is why we choose PD controller in models.

\subsection{Fast Catamaran Motion Control System}

The fast catamaran motion control system works in this scheduler: select a reference place on the board, and calculate the average vertical displacements $\left(D_{L}\right.$ and $D_{R}$ ) generated by longitudinal motions and roll motion, respectively. If $D_{L}>D_{R}$, then the longitudinal motions control model (LM) is activated; else the roll motion control model (RM) is activated (Figure 1).

Figure 2 (a) shows the longitudinal motions control simulation model. In this model, the catamaran suffers from the Froude-Kriloff force and diffraction force, the sum of which in this model generates heave force $F_{3}$ and pitch moment $F_{5}$. The $F_{3}$ and $F_{5}$ impel catamaran to make longitudinal coupling movement (heave: $z^{*}$, pitch $\theta^{*}$ ). $G_{L}(s)$ is the transfer function of 


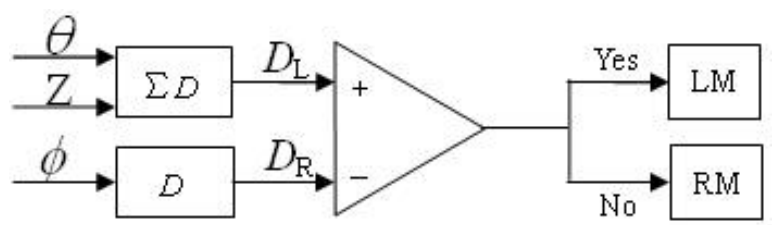

Figure 1 The switch between longitudinal motions control model and roll motion control model

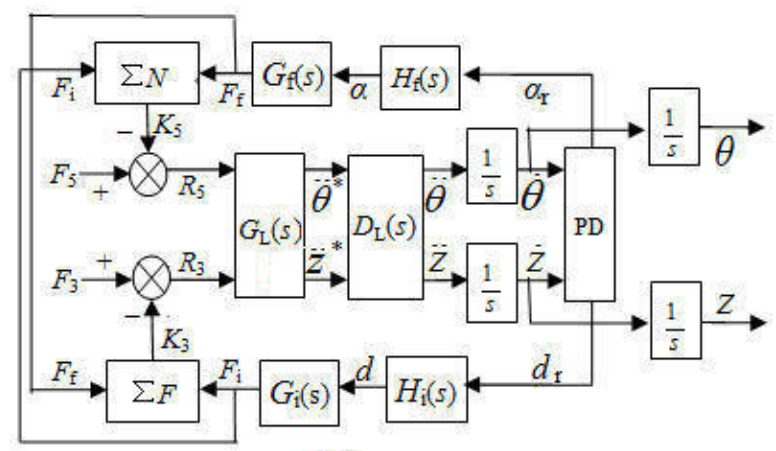

(a)

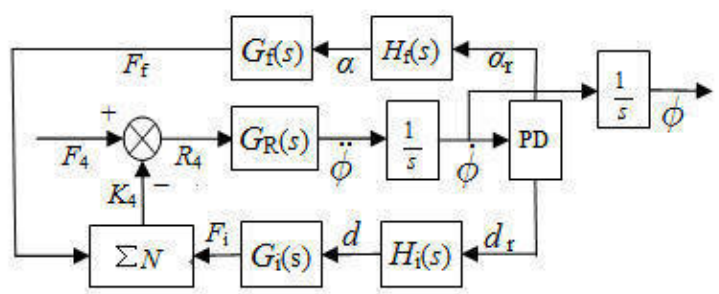

(b)

Figure 2 The fast catamaran motion control simulation models: (a) Longitudinal motions control model; (b) Roll motion control model

force-to-motion, and $D_{L}(s)$ is the decoupling model (Figure 3). After decoupling, the PD controller according to the velocities of longitudinal motions allocates the reference attack angle of T-foils $\alpha_{r}$ and inserts depth of interceptors $d_{r}$. Note that in the longitudinal motion control model, the T-foils or interceptors act simultaneously. The reference values are executed by service systems $\left(H_{f}(s)\right.$ for T-foils and $H_{i}(s)$ for interceptors) and the actual movements of actuators are $\alpha$ and d. Then the control force generated by stabilizers can be calculated according to the analyzed methods $\left(G_{f}(s)\right.$ for T-foils and $G_{i}(s)$ for interceptors), and it is easy to evaluate the counteracting force/ moments. The transfer function of force-to-motion GL(s) can be derived from formula (6) by Laplacian translation

$$
\begin{aligned}
& G_{L}(s)= \\
& s^{2}\left[\begin{array}{rr}
\left(m+a_{33}\right) s^{2}+b_{33} s+c_{33} & a_{35} s^{2}+b_{35} s+c_{35} \\
a_{53} s^{2}+b_{53} s+c_{53} & \left(I_{y}+a_{55}\right) s^{2}+b_{55} s+c_{55}
\end{array}\right]^{-1} \\
& =\left[\begin{array}{rr}
C_{11}(s) & C_{12}(s) \\
c_{21}(s) & C_{22}(s)
\end{array}\right]
\end{aligned}
$$

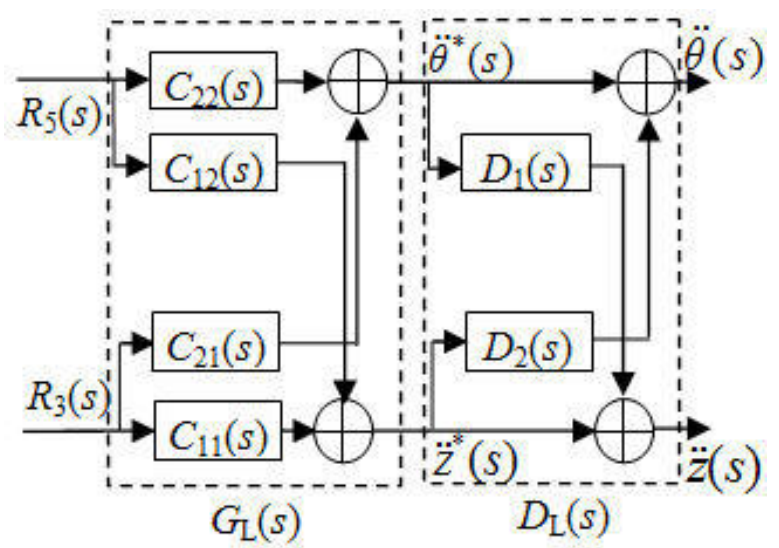

Figure 3 The decoupling model of longitudinal motions control system

Then the decoupling functions can be solved by the relations

$$
\begin{aligned}
& R_{3}(s) C_{11}(s) D_{2}(s)+R_{3}(s) C_{21}(s)=0 \\
& R_{5}(s) C_{22}(s) D_{1}(s)+R_{5}(s) C_{12}(s)=0
\end{aligned}
$$

that is

$$
\begin{aligned}
& D_{1}(s)=-\frac{C_{12}(s)}{C_{22}(s)} \\
& D_{2}(s)=-\frac{C_{21}(s)}{C_{11}(s)}
\end{aligned}
$$

Figure 2 (b) depicts the roll motion control model, the difference between which and the longitudinal one is that the latter is a two in two out coupled system, while the former is a single in single out system. In the roll motion control model the actuators act in this way: the T-foils from different sidehulls move contrarily, so do the interceptors. In this case, the induction of longitudinal motions by the roll control force/moment can be avoided, because the CFD calculation and towing experiments both prove that the control force generated by the adopted T-foil and interceptor are approximately in the same scale, which can avert the generation of the pitch moment.

Figure 2 (a) and (b) are catamaran motion control simulation models. The feedback signals and input of controllers $F_{i}, K_{i}(\mathrm{i}=3,4,5)$ are available on simulation but not in a real system. However, it is easy to realize the control scheme in reality, where the left side (splited by dashed lines) of control model in Figure 2 (a) and (b) can be replaced by material object (hull, actuators ) and wave affect (see Figure 4) whilst the right sides keep left.

\section{Numerical simulation of the catamaran mo- tion control system}

In this section, the numerical simulation results are presented. The numerical experiments are carried out 


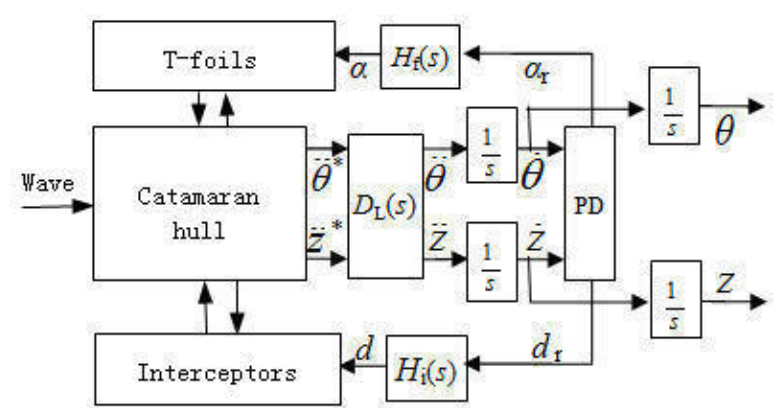

(a)

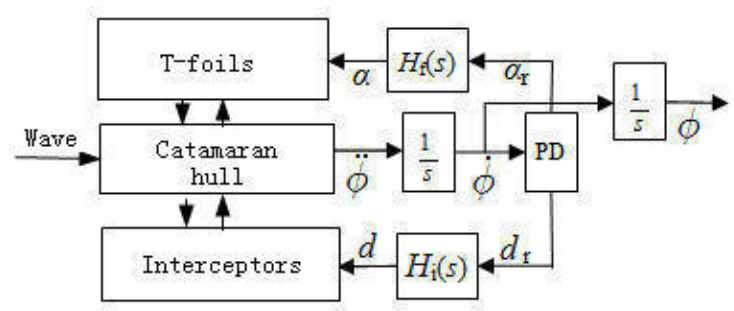

(b)

Figure 4 The fast catamaran motion control models: (a) Longitudinal motions control model; (b) Roll motion control model

based on two sea conditions: head seas and beam seas. Both seas are regular waves with unit amplitude. Under each sea conditions 10 different wave encounter frequencies are set and the hydrodynamic coefficients of the catamaran are calculated in each encounter frequency. For longitudinal motions control simulation, the simulation results consist of root mean square (RMS) of uncontrolled and controlled displacement of the bow, whose place can reflect the superimposed effect of heave and pitch. For roll motion control simulation, the simulation results consist of root mean square of uncontrolled and controlled roll angle. Besides, the motion amelioration percentage is also presented. The simulation results are adjusted to the best by tuning the PD parameters, i.e. the PD control parameters are empirically set but not by evaluation.

Some basic parameters of the fast catamaran and stabilizers are as follows.

\section{Catamaran:}

- Length: $54 \mathrm{~m}$;

- Breadth: 16.7m;

- Draught: $2.5 \mathrm{~m}$;

- Dead weight: 532t;

- Navigation speed: 40kn.
T-Foil:

- Area: $2.8 m^{2}$;

- Attack angle range: $-8^{\circ} \sim 12^{\circ}$;

- Rotation speed: $15 \%$;

- Derivative of lift coefficient $C_{L}: 0.0784 /^{\circ}$.

Interceptor:

- Breadth: $3.8 \mathrm{~m}$;

- Insert depth range: $0 \sim 80 \mathrm{~mm}$;

- Insert speed: $50 \mathrm{~mm} / \mathrm{s}$.

- Lift force of interceptor:

$$
F_{i}=\left(0.3+0.24 h+0.0025 h^{2}+6.5 q\right) g
$$

Other coefficients like added masses, damping coefficients and restoring coefficients of catamaran, Tfoils and interceptors can be evaluated by upper explained methods. Hence the simulation of catamaran motion control is realizable. Figure5. shows an example of temporal response of catamaran bow heave motion. For saving the space, only the simulation results and the corresponding encounter frequencies are presented in Table 1 and Table 2.

Table 1 Simulation results of the fast catamaran longitudinal motion control in head seas

\begin{tabular}{|l|l|l|l|}
\hline \multirow{2}{*}{$\begin{array}{l}\text { Encounter } \\
\text { frequency } \\
\omega_{e}: \mathbf{r a d} / \mathbf{s}\end{array}$} & \multicolumn{3}{|c|}{$\begin{array}{c}\text { RMS of the catamaran } \\
\text { bow displacement: } \mathrm{m}\end{array}$} \\
\cline { 2 - 4 } & Uncontrolled & Controlled & Amelioration \\
\hline 0.478 & 0.548 & 0.228 & $58.4 \%$ \\
\hline 0.919 & 0.543 & 0.122 & $77.6 \%$ \\
\hline 1.425 & 0.378 & 0.140 & $63.0 \%$ \\
\hline 1.750 & 0.394 & 0.169 & $56.8 \%$ \\
\hline 1.996 & 0.172 & 0.0368 & $78.6 \%$ \\
\hline
\end{tabular}

The average amelioration effects of the control on the longitudinal and roll motion are $65.2 \%$ and $80.2 \%$, respectively. The numerical results are satisfactory, which suggest that our catamaran motion control system is correctly designed and runs finely.

\section{Conclusions}

In this paper, a bad seakeeping performance in moderate to rough sea conditions, the drawback of the fast catamaran ferry is discovered and analyzed. Then existing stabilizers and methodologies for the purpose 

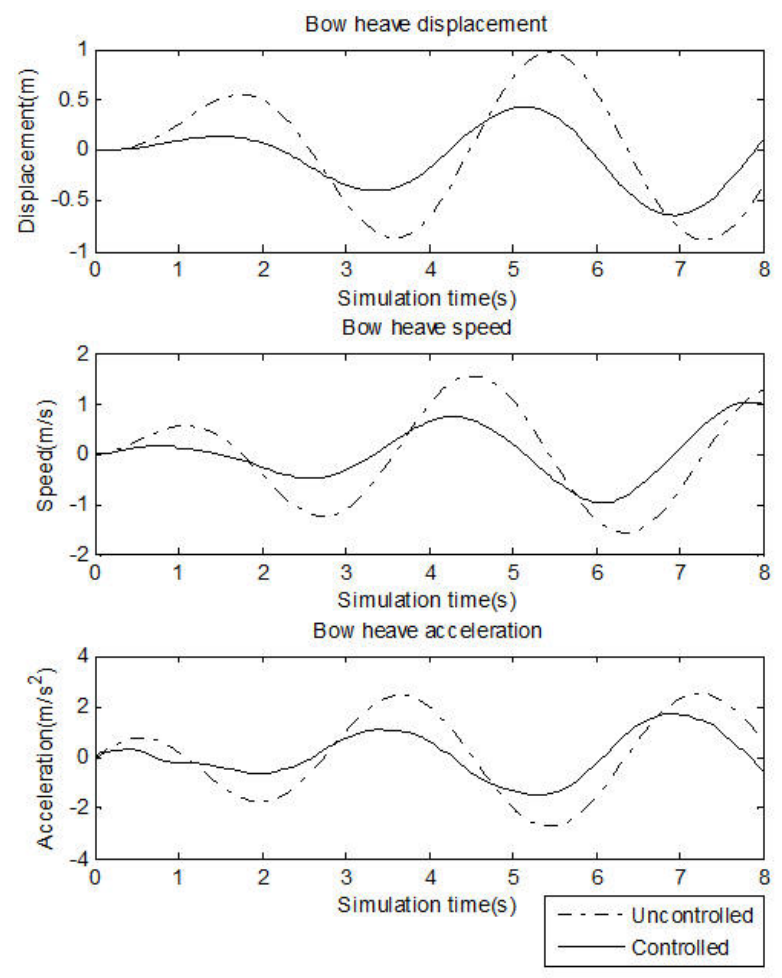

Figure 5 A temporal response of catamaran bow heave motion on encounter wave frequency e $=1.750 \mathrm{rad} / \mathrm{s}$ under control / without control.

Table 2 Simulation results of the fast catamaran roll motion control in beam seas

\begin{tabular}{|l|l|l|l|}
\hline $\begin{array}{l}\text { Encounter } \\
\text { frequency }\end{array}$ & \multicolumn{3}{|c|}{ RMS of the catamaran roll angle: } \\
\cline { 2 - 4 }$\omega_{e}: \mathbf{r a d} / \mathbf{s}$ & Uncontrolled & Controlled & Amelioration \\
\hline 0.478 & 1.58 & 0.275 & $82.5 \%$ \\
\hline 0.919 & 4.20 & 0.194 & $95.4 \%$ \\
\hline 1.389 & 1.50 & 0.138 & $90.8 \%$ \\
\hline 1.711 & 0.945 & 0.390 & $59.0 \%$ \\
\hline 2.033 & 1.30 & 0.44 & $73.5 \%$ \\
\hline
\end{tabular}

of seakeeping improvement are carefully investigated. An important fact is pointed out that the seakeeping amelioration should include both longitudinal and transverse motions improvement, which means that the roll stabilizer - fins and heave/pitch stabilizers - T-foil and interceptor, are simultaneously required.

But in this paper, authors find out that for catamarans, which have wide breadth, the longitudinal motions stabilizers T-foils and interceptors can also generate enough roll moment to counteract the wave stimulated. Based on this discovery, an ingenious 3-DOF motions autonomous control system is built up. This system can freely make switch to control the longitudinal motions or roll motion.

In this paper the hydrodynamic characteristics of the catamaran, T-foils and interceptors are also studied. A post-compensation decoupling method is proposed to decouple the coupled longitudinal motions. A practical control algorithm - PD controller is employed in the control system.

Numerical simulation results are also presented in this paper, which show that the designed system can satisfactorily control the longitudinal and roll motions of the fast catamaran.

In our future work, the control model will be realized and towing experiments will be carried out.

\section{Acknowledgments}

This work is supported by the Fundamental Research Funds for the Central Universities under Grant HEUCF110118 and by the National Natural Science Foundation under Grant 61004008.

\section{References}

[1] E.M. Kogan, "To hydrodinamical theory of oscillations of catamaran in liquid of finite depth", Proc. Nikolaev Shipbuilding Institute of adm. S.O. Makarov. Ship theory, vol.35, pp.33-39, 1970.

[2] E.M. Kogan, "To the calculation of main part of disturbing forces for oscillating catamaran in liquid of finite depth”, Proc. Nikolaev Shipbuilding Institute of adm. S.O. Makarov. Ship theory, vol.44, pp.42-45, 1971.

[3] Chih-Chung Fang, Hoi-Sang Chan, "An investigation on the vertical motion sickness characteristics of a high-speed catamaran ferry", Ocean Engineering. vol.34, pp.1909-1917, 2007.

[4] Osman Turan, Chirstos Verveniotis and Hassan Khalid, "Motion sickness onboard ships: subjective vertical theory and its application to full-scale trials", vol.14(4), 409-416, 2009.

[5] Vasilij Dyachkov, Jurij Makov, "Seakeeping of a fast displacement catamaran", Transport, vol.XX(1), pp.14-22, 2005.

[6] A.R.J.M., Lloyd, "Hydrodynamic performance of roll stabilizer fins", 3rd SCSS, Bath, 1972.

[7] W.E. Cowley, "The use of rudder as roll stabilizer", 3rd SCSS, Bath, 1972.

[8] Hongbo Wang, Yiping Guo, Zhao Pan, "Simulation study on ship motion control algorithm based on AOCS structure", Proc. ICECE, pp.1946-1949, 2010.

[9] M.T. Sharif, G.N. Roberts and R. Sutton, "Final experimental results of full scale fin/rudder roll stabilisation sea trials", Control Eng. Practice, vol.4(3), pp.377-384, 1996. 
[10] Yingzhong Liu, Guoping Miao, Ship motion in wave, University of Shanghai Jiaotong Press, Shanghai, 1986.

[11] Odd M. Faltinsen, "Hydrodynamics of high-speed marine vehicles", Cambridge University Press, 2005.

[12] J. M.Giron-Sierra, S. Esteban, et al, "Overview of a research on actuators control for better seakeeping in fast ships", Proc. IFAC, 2005.

[13] S. Esteban, J.M. De La Cruz, et al, "Fast ferry vertical accelerations reduction with active flaps and T-foil", Proc. IFAC MCMC, pp.233-238, 2000.

[14] J.M. Giron-Sierra, S. Esteban, B.De Andres, J.M. Diaz and J.M. Riola, "Experimental study of controlled flaps and T-foil for comfort improvement of a fast ferry", Proc. IFAC CAMS, 2001.

[15] S. Esteban, J.M.Giron-Sierra, B. De Andres, J.M. De La Cruz, and J.M. Riola, "Fast Ships models for seakeeping improvement studies using flaps and T-foil", Mathematical and Computer Modelling, vol.41(1), pp.1-24, 2005.

[16] J.M. Giron-Sierra, S. Esteban, "Frequency domain study of longitudinal motion attenuation of a fast ferry using a T-foil", Proc. IFAC, pp.15004-15009, 2008.

[17] J. Aranda, R. Munoz-Mansilla, J.M. Diaz, "The problem of the vertical movement control with roll movement in fast ferries", Proc. CAMS IFAC, pp.339-344, 2004.

[18] J. Recas, J.M. Giron-Sierra, S. Esteban, et al, "CANbus based system for course and ride control in fast ship autonomous model”, IASME Trans., vol.1(2), pp.265-270, 2004.

[19] J. Aranda, R. Munoz-Mansilla, J.M. Diaz, C. Dormido, "Robust control for the coupling of transverse and longitudinal dynamics in high-speed crafts", Proc. IFAC World Congress, 2005.
[20] Naoki Ohba, Taketsune Matsumura, Akihiko Imakita, "Motion control in waves of a $140 \mathrm{~m}$ SES", Proc. 7th JFPS Int. Sym. on Fluid Power, pp.121-126, 2008.

[21] Qiang Liu, "Research on scheme optimization of stabilizing fin and longitudinal motion control of SWATH", Dissertation of Eng. Doctor Degree, Harbin Engineering University, 2008.

[22] Motoki Yoshida, Hajime Kihara, Hidetsuqu Iwashita, Hiroshi Itakura, Weiguang Bao and Takeshi Kinoshita, "The effect of controlling fins on the motion of resonance-free SWATH (RFS) platform", Proc. 29th International Conference on Ocean, Offshore and Arctic Engineering, vol.3, pp.57-64, 2010.

[23] O. Faltinsen, R. Zhao, "Numerical predictions of ship motions at high forward speed", Philos Trans. $R$ Soc Lond, A 334, pp.241-252, 1991.

[24] Wenyang Duan, Shan Ma, Jingzheng Song, "Hydrodynamic properties of high-speed catamarans", Journal of Harbin Engineering University, vol.23(1), pp.9-14, 2002.

[25] Alexander H. Day, Christopher Cooper, "An experimental study of interceptors for drag reduction on high-performance sailing yachts", Ocean Engineering, in press, 2011.

[26] Kejun Wang, Xuliang Yao, Hongzhang Jin, "Control theory of marine craft", Harbin Engineering University Press, 2005.

[27] Shujuan Wang, Jihong Shen, Jide Li, "Numerical ducoupling of ship vertical motion system", Journal of Dalian Maritime University, vol.36(1), pp.14-18, 2010 . 